\title{
Extra-anatomical intraduodenal endoscopic-radio- logic biliary rendezvous for treatment of iatrogenic complete stenosis of the common bile duct
}

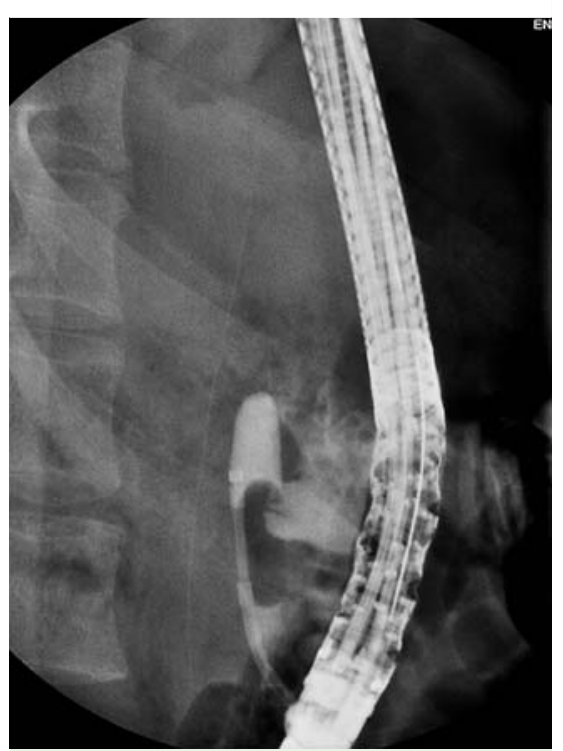

Fig. 1 Occlusive retrograde cholangiogram showing complete stenosis of the common bile duct (CBD) in a 38-year-old woman. This occurred after removal of a stent placed to manage an iatrogenic biliary fistula with partial stenosis of the CBD that had developed following laparoscopic cholecystectomy.

Minimally invasive radiologic-endoscopic recanalization or reconstruction of the common bile duct (CBD) for benign complete stenosis or complex iatrogenic lesions is routinely practiced at some tertiary centers $[1,2]$. Various techniques have been reported, including endoscopic ultrasound (EUS)-guided insertion of a magnet through a previous choledochoduodenostomy [1-4].

A 38-year-old woman who had undergone laparoscopic cholecystectomy 6 months earlier developed an iatrogenic biliary fistula with partial stenosis of the CBD. A biliary fully covered self-expanding metallic stent (FCSEMS) was placed for 2 months, but jaundice and pain recurred 3 months after its removal. Occlusive endoscopic retrograde cholangiography revealed complete stenosis at the mid CBD ( $\bullet$ Fig. 1 ).

A guidewire was maneuvered to perforate the CBD at a point distal to the stricture, and percutaneous transhepatic cholangiographic guidance was used to perforate the hepatic duct with a guidewire at a point proximal to the stricture ( $\boldsymbol{O}$ Fig. 2 ). How-

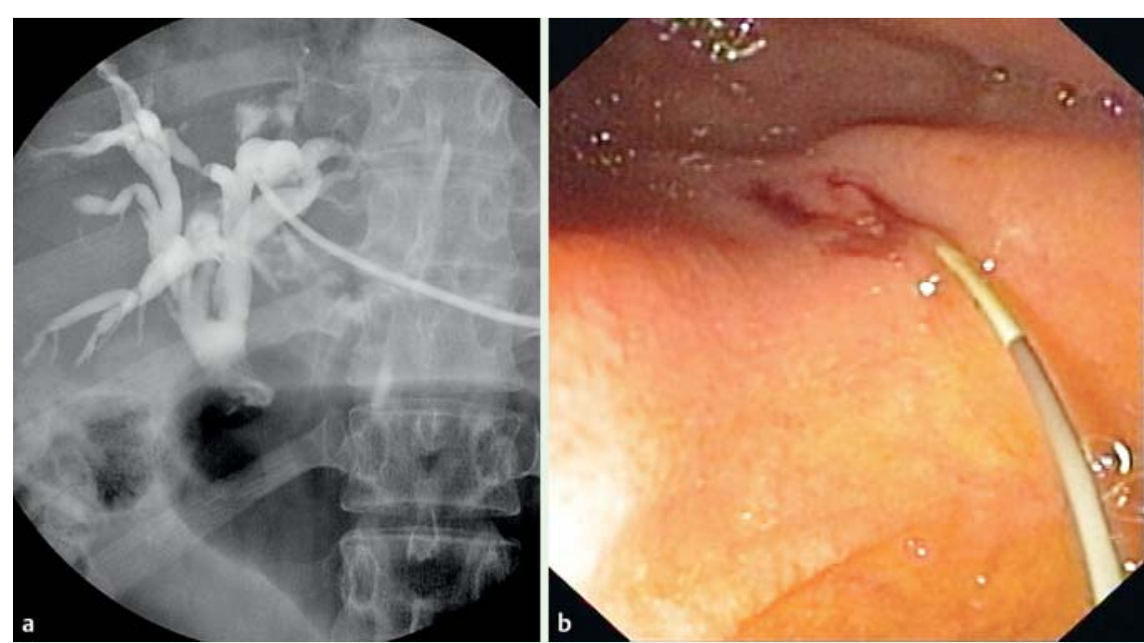

Fig. 2 a Percutaneous transhepatic cholangiogram showing common bile duct cutoff. $\mathbf{b}$ The guidewire that had been inserted percutaneously passed through the choledochal stenosis and reached duodenal bulb.

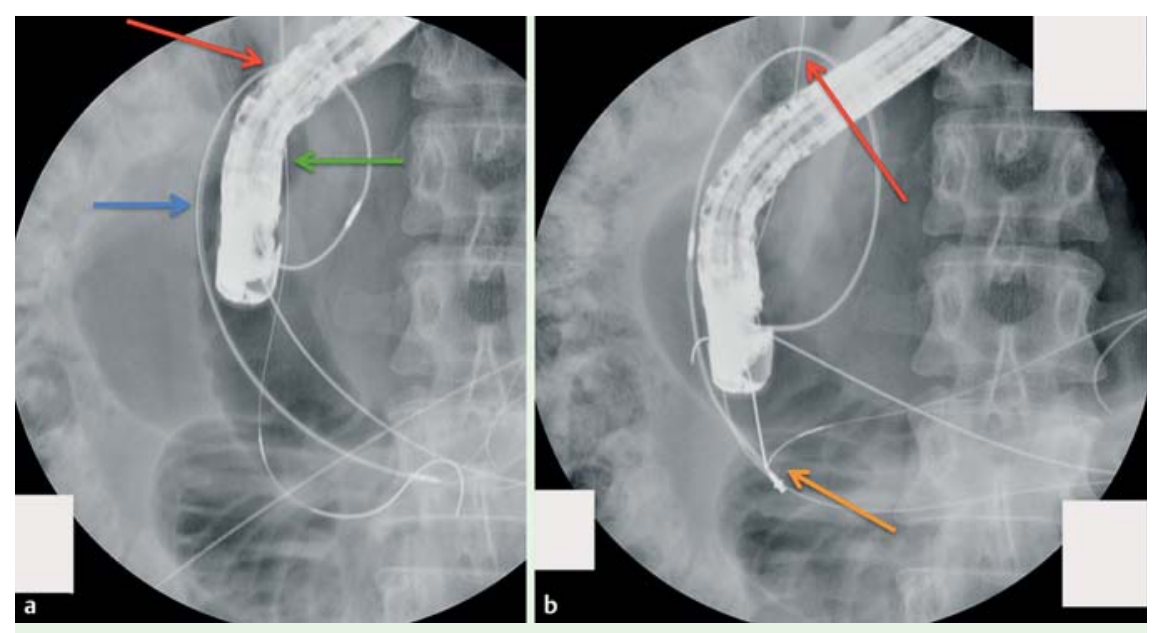

Fig. 3 a, b Extra-anatomical intraduodenal endoscopic-radiologic biliary rendezvous. Both guidewires reach the duodenal bulb through the same hole (red arrows). a A Dormia basket is inserted endoscopically and pushed into the lumen of the duodenal bulb (blue arrow). The proximal guidewire that has been inserted percutaneously can be seen (green arrow). b Rendezvous (orange arrow) is achieved by grasping the guidewire that has been inserted percutaneously and reached the lumen of the duodenal bulb.

ever both guidewires tended to advance in the direction of the duodenal bulb, and several attempts to achieve a rendezvous in the subhepatic space failed. Therefore, we then advanced both guidewires along the preferential route to reach the duodenal bulb through the same hole, created by the guidewire ( $\bullet$ Fig. 3 a), thus avoiding significant duodenal injury. Next, with a Dormia basket that had been inserted endoscopically, the proximal guidewire was grasped ( $\bullet$ Fig. $\mathbf{3 a}, \bullet$ Fig.3b) and constant, controlled traction was applied to extra-anatomically establish continuity of the biliary tree ( $\odot$ Fig. $\mathbf{4 a}$, $\odot$ Fig. $\mathbf{4 b}$, - Fig.4c). An FCSEMS (Wallflex; Boston Scientific, Natick, Massachusetts, USA) was delivered for definitive treatment and scheduled to be replaced after 6 months $(\bullet$ Fig.5). The patient was discharged 


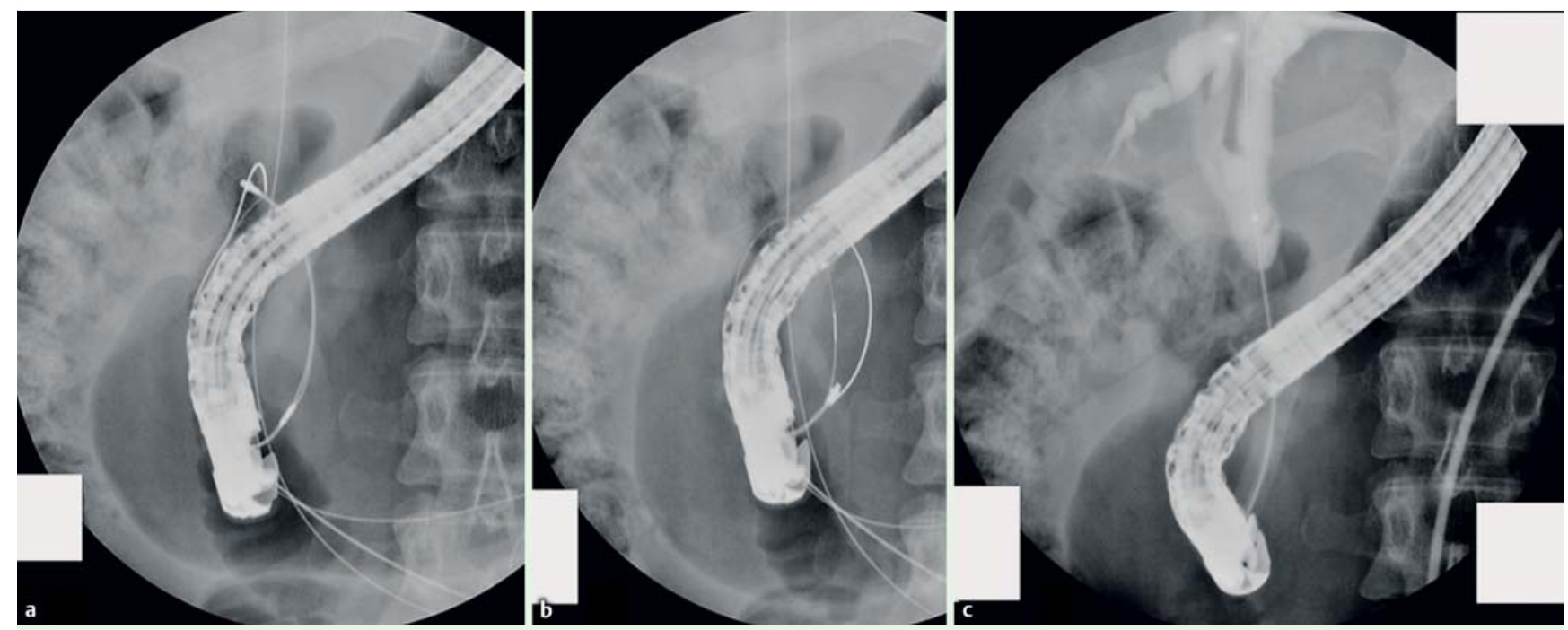

Fig. 4 a, b Constant, controlled traction is applied following the rendezvous. c Biliary continuity is re-established.

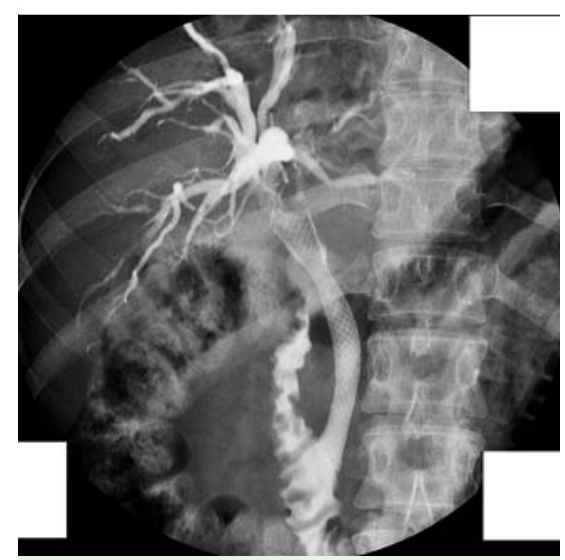

Fig. 5 The fully covered metal stent in place, draining the hepatic ducts proximal to the stricture into the common bile duct distal to the stricture.

from the hospital the next day on a normal diet.

Endoscopic-radiologic reconstruction of an injured bile duct is a feasible and safe technique that spares the patient the major surgery of bilioenteric reconstruction. We report here the first case of extra-anatomical (i.e., intraduodenal) ren- dezvous to re-establish biliary continuity in a patient with an iatrogenic complete stricture. This report should encourage the use of other alternative methods, such as "pure EUS-guided endoscopic biliary rendezvous," that make it possible to avoid the step of subhepatic rendezvous, which has been problematic until now.

Endoscopy_UCTN_Code_TTT_1AR_2AD

Competing interests: None

Bruno Meduri ${ }^{1}$, Serge Derhy²,

Parag Dhumane ${ }^{3}$, Jean-Loup Dumont ${ }^{1}$, Thierry Tuszynski ${ }^{1}$, Bertrand Marie Vergeau ${ }^{1}$, Gianfranco Donatelli ${ }^{1}$

${ }^{1}$ Unité d'Endoscopie Interventionnelle, Ramsay Générale de Santé, Hôpital Privé des Peupliers, Paris, France

2 Unité de Radiologie Interventionnelle, Ramsay Générale de Santé, Hôpital Privé des Peupliers, Paris, France

${ }^{3}$ Department of General and Laparoscopic Surgery, Lilavati Hospital and Research Center, Bandra West, Mumbai, India

\section{References}

1 Fiocca F, Salvatori FM, Fanelli $F$ et al. Complete transection of the main bile duct: minimally invasive treatment with an endoscopic-radiologic rendezvous. Gastrointest Endosc 2011; 74: 1393 -1398

2 Donatelli G, Vergeau BM, Derhy S et al. Combined endoscopic and radiologic approach for complex bile duct injuries (with video). Gastrointest Endosc 2014; 79: 855-864

3 Harma V, Raghavendra Prasada KV, Rana SS et al. A modification of rendezvous technique for endoscopically treating transected common bile duct following cholecystectomy. J Dig Endosc 2014; 5: 129-131

4 Perez-Miranda M, Aleman $N$, de la Serna Higuera $C$ et al. Magnetic compression anastomosis through EUS-guided choledochoduodenostomy to repair a disconnected bile duct in orthotopic liver transplantation. Gastrointest Endosc 2014; 80: 520-521

\section{Bibliography}

Dol http://dx.doi.org/

10.1055/s-0034-1393383

Endoscopy 2015; 47: E565-E566

(c) Georg Thieme Verlag KG

Stuttgart · New York

ISSN 0013-726X

Corresponding author

\section{Gianfranco Donatelli, MD}

Unité d'Endoscopie Interventionnelle

Ramsay Générale de Santé

Hôpital Privé des Peupliers

8 Place de l'Abbé G. Hénocque

75013 Paris

France

Fax: +33-01-44-16-56-15

donatelligianfranco@gmail.com 